\title{
Imprisoning the mentally ill
}

I $\mathrm{t}$ was, to be sure, a sobering and disturbing observation. "Federal penitentiaries are fast becoming our nation's largest psychiatric facilities and repositories for the mentally ill," Correctional Investigator of Canada Howard Sapers wrote in a report on the state of affairs in the nation's federal prisons. "As a society, we are criminalizing, incarcerating and warehousing the mentally disordered in large and alarming numbers," he added (www.oci -bec.gc.ca/rpt/annrpt/annrpt20092010 -eng.aspx).

Sapers subsequently supported that conclusion in a later report indicating that more than 1 in 10 men and nearly one in three women in federal prisons have mental health problems and that $30.1 \%$ of female offenders and $14.5 \%$ of male offenders had been previously hospitalized for psychiatric reasons (www.oci-bec.gc.ca/rpt/annrpt/annrpt 20112012-eng.aspx\#s4).

So prevalent is the incidence of mental health problems in prisons that experts have identified the burden as being three times that of the general Canadian population (Behav Sci Law 2009;27:811-31). And it's not a phenomenon that's unique to Canada. Among developed nations, roughly one in seven inmates has a psychotic illness or major depression, according to one study (Lancet 2002;359:545-50).

Some have argued that the root of the problem can be traced to the discovery and use of psychotropic medications in the 1950s. The routine use of these agents helped stabilize institutionalized psychiatric patients, allowing them to be discharged, on an outpatient basis, for reintegration with the community. The movement, known as "deinstitutionalization," resulted in the virtual emptying, and subsequent closure, of many psychiatric facilities across the country (Can J Psychiatry 2012;57[2]:Insert 1-6).

Not without consequence, though. The comprehensive community support systems that were meant to sustain deinstitutionalization never fully material-

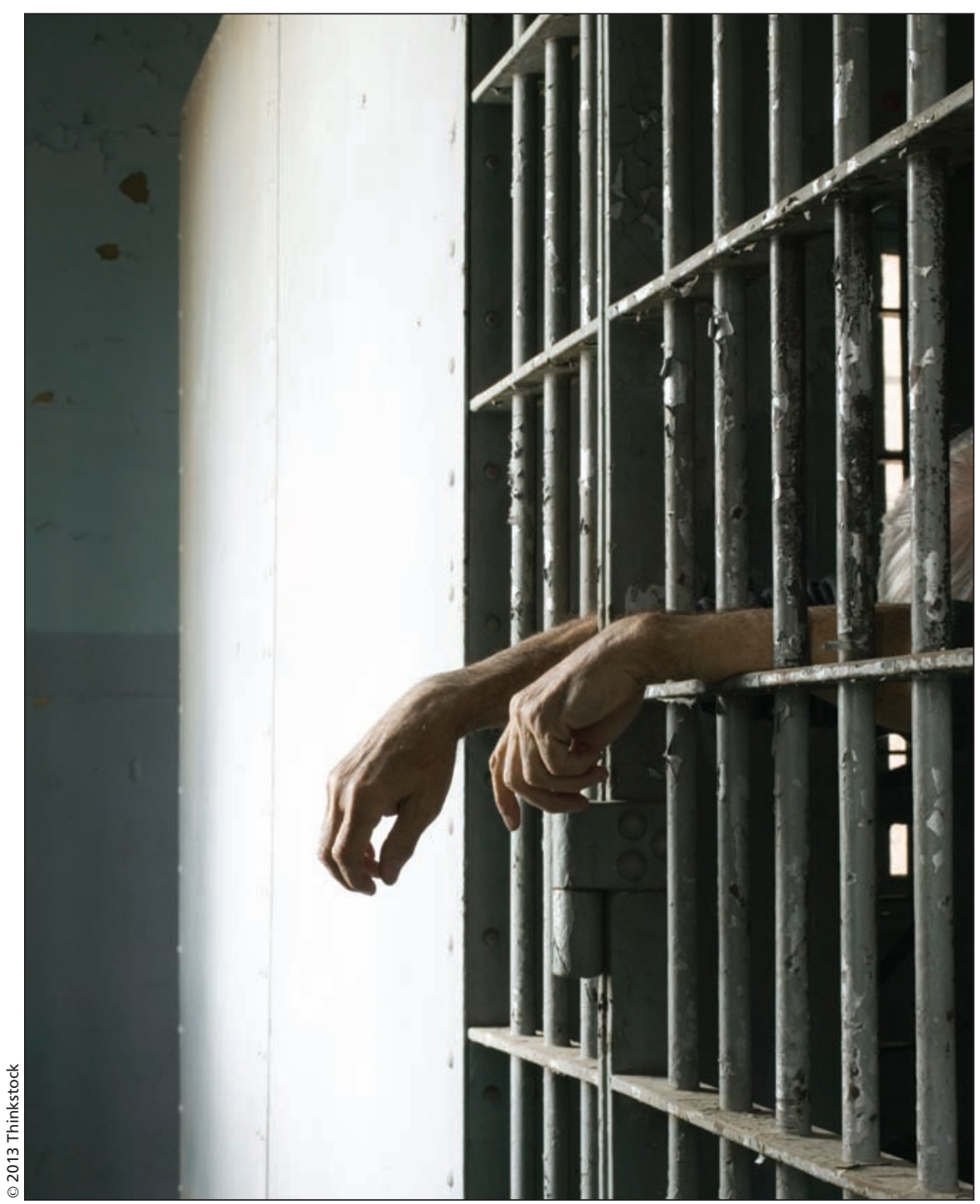

Correctional Investigator of Canada Howard Sapers estimates that 1 in $\mathbf{1 0}$ men and nearly one in three women in federal prisons have mental health problems.

ized. The shortfall, along with the closure of inpatient psychiatric institutions, soon resulted in an increasing number of patients engaging with the criminal justice system, a process that was quickly dubbed "transinstitutionalization."

"The consequence of deinstitutionalization has essentially been an increase in the mentally ill showing up in corrections facility," says Dr. Gary Chaimowitz, head of forensic psychiatry at St. Joseph's Healthcare Hamilton in Ontario. "Corrections have become the institution of last resort for people with serious mental illness."

Chaimowitz argues that is classic evidence of Penrose's Law, which holds that the population size of prisons and psychiatric hospitals are inversely related. The British psychiatrist, Lionel Penrose, also posited that if the population of either were restricted, the other would increase (Br J Med Psychol 1939; 18[1]:1-15).

That certainly appears true in Canada. In 1959, the nation had 65000 beds in 
mental health facilities (Can J Psychiatry 2012;57[2]:Insert 1-6). Today, there are just 10653 beds (www.who.int/mental _health/evidence/atlas/profiles/can_mh _profile.pdf).

Over essentially the same time period, the number of incarcerated Canadian adults has leapt to 140 per 100000 population (www.statcan.gc.ca /pub/85-002-x/2012001/article/11715 -eng.htm\#a3) from 80 per 100000 (www .csc-scc.gc.ca/text/pblct/forum/e123 /e123h-eng.shtml).

But transinstitutionalization isn't the sole factor at play in the disproportionate incarceration of the mentally ill, several experts say. They point to Prime Minister Stephen Harper's "get-tough-on-crime agenda" as also having had a substantial impact on the numbers of incarcerated.

Statistics Canada indicates that roughly 38000 offenders were in federal or provincial jails on any given day in fiscal 2010/11 (www.statcan.gc .ca/pub/85-002- $x / 2012001 /$ article/11715 -eng.htm). That represented a $1 \%$ increase over the previous fiscal year and roughly a $5 \%$ increase over the course of a decade. It resulted in Canada being ranked 17th in incarceration rates among 34 Organisation for Economic Co-operation and Development member nations.

A disproportionate share of the men- tally ill are represented in those who've been caught up in the get-tough-oncrime agenda, says Chaimowitz, who is also past-president of the Canadian Academy of Psychiatry and the Law. "When you start arresting and incarcerating people for petty offenses you're going to pick up more individuals with mental illness; it does skew towards incarceration of the mentally ill. ... At the end of the day, I don't think it will do anything but increase the incarceration of the mentally ill."

As a corollary, the conditions of confinement essentially increase the rate of mental illness, Sapers notes. "There is an increase in the population of those who are becoming or developing mental health problems while incarcerated. This seems to be related to a whole host of conditions related to conditions of confinement."

Part of that is a function of overcrowding, which results in the practice of double-bunking. "We're simply incarcerating more people," Sapers notes. "There are approximately 1000 more offenders inside Canadian federal institutions over the last couple of fiscal years. We've seen a relatively large increase: the equivalent of two medium security institutions. But we haven't seen two medium security institutions open up. So they're being stacked in existing institutions."
As a consequence of that doublebunking, "we're seeing more mental illness because the conditions are worsening," Sapers adds. "You're fitting more people into already crowded facilities; you're creating negative conditions of confinement, which does have an impact on people's mental health."

That will likely continue in the future. As of March 2012, the national rate of double-bunking was $17.18 \%$, representing over 2300 inmates, an increase of roughly $33 \%$ over the number who were double-bunked in March 2011 (www.oci-bec.gc.ca/rpt/annrpt /annrpt20112012-eng.aspx\#s4).

The government is hopeful, though, that the trend will be reversed as the construction of new facilities is completed. Roughly 2700 new cells are currently being constructed.

The question, though, is whether Canada is now caught in what Sapers calls the "gap between when policy changes and it creates new burdens on the system and when the system has the capacity to respond," or whether there are far more systemic problems with Canada's approach to the provision of health services for the incarcerated. Nathan Stall MD, Toronto, Ont.

CMAJ 2013. DOI:10.1503/cmaj.109-4390

\section{Agony behind bars}

\section{M} ost Canadians are familiar with the shocking video footage that was presented in a coroner's court in 2012 as part of an inquest into the Oct. 19, 2007 selfstrangulation of teenager Ashley Smith inside a solitary confinement cell at the nation's only federal women's prison, the Grand Valley Institution for Women in Kitchener, Ontario.

It's hard to imagine that any of the verbal evidence to be presented this month at the inquest will be more plaintive than the chilling "how can it get worse?" Smith asked as Royal Canadian Mounted Police bound her wrists together with duct tape during a 2007 prison transfer between Saskatoon, Saskatchewan and Montréal, Quebec.
But the fact is that for thousands of other mentally ill inmates in Canada's prisons, experts say, things are altogether likely to get much worse.

While the deinstitutionalization movement and the "get-tough-oncrime" agenda of Prime Minister Stephen Harper's government have contributed to the rising number of mentally ill people who are incarcerated (www.cmaj.ca/lookup/doi/10.1503 /cmaj.109-4390), that doesn't begin to account for the effects of deficiencies in care provided to the mentally ill who are incarcerated.

The critics charge that correctional facilities are no form of therapeutic haven for the afflicted and that once in prison, mental health needs typically go unde- tected or untreated. Mentally ill inmates are left to decompensate psychiatrically.

Or as Correctional Investigator of Canada Howard Sapers notes: "Many mentally disordered inmates do not manage well in a prison environment."

"Some manifest symptoms of their illness through disruptive behaviour, aggression, violence, self-mutilation, suicidal ideation, withdrawal, refusal or inability to follow prison orders or rules," Sapers earlier stated in his 20112012 report (www.oci-bec.gc.ca/rpt /annrpt/annrpt20112012-eng.aspx\#s4). "Within corrections, these symptoms of mental illness are often misunderstood as manipulative or malingering behaviour, and are regularly met by a range of inappropriate responses including disci- 